\title{
Performance Analysis of Various Routing Protocols in 3D Body Architecture using Qualnet in WBSN
}

\author{
Deepak Sethi ${ }^{1}$, Partha Pratim Bhattacharya ${ }^{2}$
}

\begin{abstract}
Wireless Body Sensor Network (WBSN) is a connectionless architecture used to monitor health of a patient or an athlete. Various routing strategies have been proposed to increase the network lifetime. In this work, we have compared some well known ad-hoc network routing protocols like DYMO, DSR, ZRP and LAR1 in WBSN. WBSN works in a small area like Bluetooth or Zigbee. Few gateway nodes are also considered to route the traffic. The simulations have been performed using Qualnet 6.1. Various parameters like jitter, throughput, end to end delay, packet delivery ratio has been used for comparison. Results revealed that ZRP have least end to end delay (0.2) and jitter (0.1), but have low throughput i.e. $2362 \mathrm{~b} / \mathrm{s}$ as compared to DYMO and DSR i.e. $2752 \mathrm{~b} / \mathrm{s}$ and $3026 \mathrm{~b} / \mathrm{s}$.
\end{abstract}

Keywords: DYMO, WBSN, ZRP, DSR, LAR1, health monitoring, patient monitoring

\section{INTRODUCTION ${ }^{1}$}

W BSN consists of wireless sensors placed around or in a human body that are used to exchange important information to remote stations [1]. Figure 1 depicts how sensor nodes can be used to sense data and transmit it through internet. Very specific requirements have been placed on nodes [2]. It should be small, consumes low power and reliable [3-4]. Due to varieties of components in WBSN, it is able to perform sensing work in military, healthcare, emergency, research, lifestyle, sports etc. Medical application of WBSN continuously monitor the patients, if any abnormal condition is detected, the information is immediately transmitted to doctor. In non-medical applications

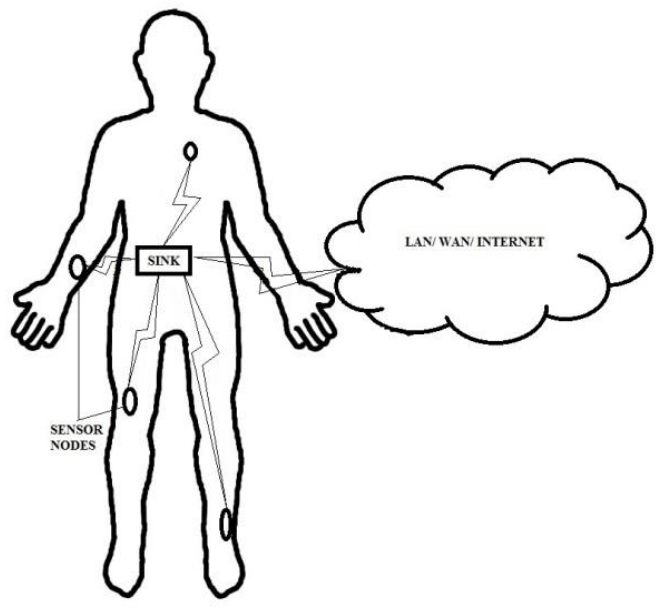

Figure. 1. Sensor nodes Deployment in Human Body

\footnotetext{
${ }^{1}$ Deepak Sethi is with College of Engineering and Technology, Mody University of Science \& Technology, Lakshmangarh, 332311,Rajasthan, India. Email: deepaksethi@live.in

${ }^{2}$ Partha Pratim Bhattacharya is with College of Engineering and Technology,Mody University of Science \& Technology, Lakshmangarh, 332311, Rajasthan, India. Email: hereispartha@gmail.com
}

especially in military, WBSNs are used to prevent sensitive information from being caught by enemies. Various applications have been discussed in [1-7]. Few of them are categorized and illustrated in figure 2 . WBSN perform in three-tier architecture as shown in figure 3. Tier-1 will serve as intra-WBAN communication and Tier-2 and Tier-3 will serve as interWBAN communication.

\section{ROUTING TECHNIQUES}

In this work, Mobile Ad-hoc NETwork (MANET) routing protocols are used in WBSN. Short introduction of them are as follows.

\section{A. Dynamic Source routing protocol (DSR)}

DSR is an on-demand routing technique used in MANETs [8]. Route discovery and route maintenance are the mechanisms which works together to allow nodes to discover and maintain source routes to destination.

For transmitting a packet from source to destination, it first checks the route in its route cache. If the route exists, then the same route is used. Otherwise, a route discovery process is initiated by broadcasting the route discovery message. DSR uses route request, route reply and route error packets for requesting, updating and maintaining the routes [14]. For avoid loops, it also supports multiple routes.

\section{B. Location Aided Routing (LAR1)}

When we want to send the route request to a specific area which contains the destination, LAR is used [9]. It also contains the GPS information. During route discovery in LAR1, source node calculate expected zone and then define a request zone. Only the node in the request zone forwards the packet. If it reached the destination node within timeout period, it will send a route reply message otherwise source initiate flooding technique. 


\section{Wireless Body Area Network}

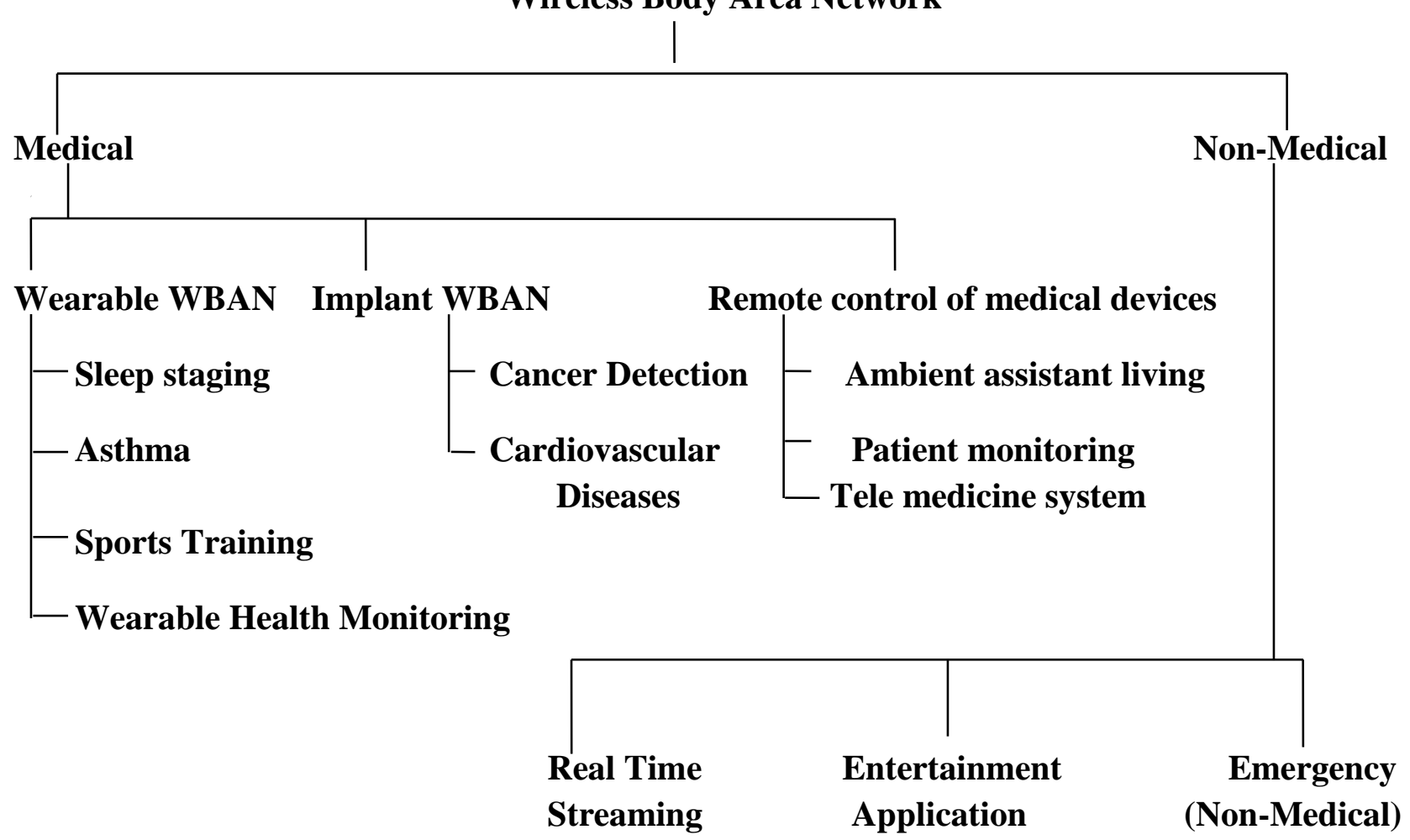

Figure. 2. Various applications of WBSN

\section{DYnamic MANET On Demand Routing Protocol (DYMO)}

DYMO is an expansion of AODV proposed by Perkins \& Chakeres [3]. It implements three messages during routing operation; Route Request (RREQ), Route Reply (RREP) and Route Error (RERR). It also uses a sequence number which is a unique integer assigned to each packet to ensure orderly and loop free delivery of packets to destination. Route discovery is similar to AODV with addition of making a backward path. Route maintenance is

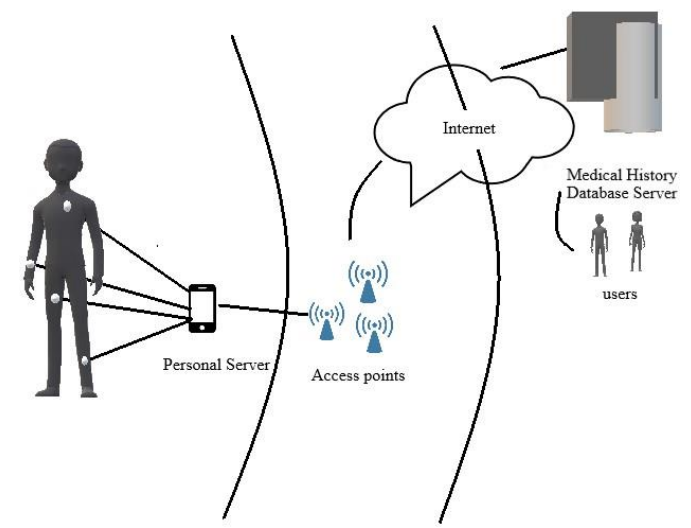

TIZR 1

TIZZR 2

TIER 9 similar to other routing protocols by generating RERR messages. The advantages of DYMO protocol are energy efficient, less overhead, low memory consumption, works efficiently on large network with high mobility. But, it does perform well when the traffic is low.

\section{Zone Routing Protocol (ZRP)}

ZRP is a hybrid protocol [11] i.e. it works like proactive routing (inside the zone), reactive routing (outside the zone) and bordercasting( for construction of map) technique. ZRP includes protocols such as IntrA-zone Routing Protocol (IARP), IntEr-zone Routing Protocol (IERP) and Bordercast Resolution Protocol (BRP). Various routing techniques have been developed. Some of them are discussed as follows.

In [14], an energy efficient network coding approach for cooperative solution is proposed using decode and forward relays sensor nodes. The different messages coming from different sources are combined and generate one message for whole messages by relay node. And then, generated messages are transmitted to the destination, this scheme is called decode and forward-network coding (DF-NC). Here, relay node works in half-duplex mode. Using this approach, minimum energy is consumed over other existing non network coding approach, because DF-NC requires only one time slot to forward the message and use direct transmission for WBANs. So, maximum energy is 
utilized and less time is required to transmit the sensed data from source to destination. In [15], authors N. Javaid and others proposed LAEEBA and COLAEEBA routing protocols to improve the network lifetime, energy consumptions as well as path loss of network in WBANs. There is a forwarder node in LAEEBA (Link Aware Energy Efficient Routing for Body Area), which is selected on the basis of residual energy of the sensor nodes. While, COLAEEBA (Cooperative Link Aware Energy Efficient Routing for Body Area) works on the basis of cooperation, and source nodes are utilized more than one link at the same time. In [16], authors proposed a dynamic resource allocation scheme to avoid the interferences amongst coexisting WBAN, using a table in which activity of nodes interference are updated. Authors also provide a mathematical analysis to validate its efficiency and a probabilistic approach to reduce the interference level. To avoid interferences among WBANs, a complete orthogonal channel is assigned to all sensor nodes in the network and at the same time, other sensor nodes re allowed to use the whole time slot until all are occupied. So this proposed scheme is efficient to reuse the channel and as well as maintain the interference level among sensor nodes in WBANs. In [17], a priority based energy aware routing is proposed, that effectively transfer the information to the sink node with supporting the mobility nature, in WBANs. A parent node is selected based on the cost function, considering priority, residual energy and distance of node. The distance factor helps in packet delivery from child to forwarder node and priority helps to select the best path to forward the critical data. In [18], a cluster based routing protocol is proposed by author to increase the stability of network and decrease the energy consumption of sensor

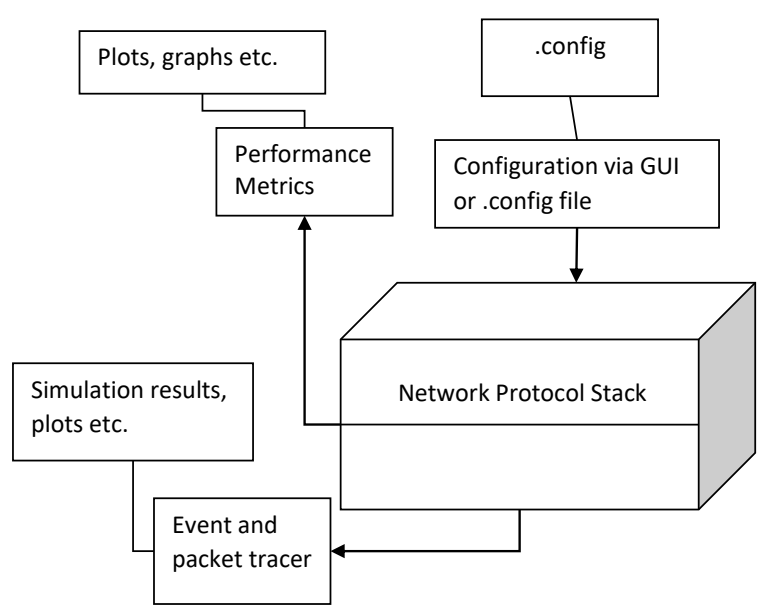

Figure. 4. QualNet Interface nodes in WBANs, inspired by modleach protocol of WSNs. Single hop and multi hop communication is used to send the emergency and normal data respectively to the sink node. Threshold value is used to select the cluster head. It will remain cluster head for next round, if energy of cluster head is greater than threshold value. So, there is no need to select the new cluster head and in this way, energy is saved. In [19], authors design an improved routing protocol for effective data transmission and consider even energy consumption called 'Even Energy Consumption and Back Side Routing Protocol' (EECBSR). The main objective behind this routing technique is to increase the lifetime of network, energy efficiency and path loss of node located at the back side of body. Its aim to reduce the problem arises in M-ATTEMPT, like not support the mobility and operation runs parallel in this work.

Since, WBAN is a human monitoring system to detect the physiological sign of the body, in which battery constraints sensor nodes are implanted. Successfully transmission of sensed data to the destination is very important. Here, few routing protocols have been compared. Simulation has been performed in Qualnet 6.1. These protocols are compared and simulated in different scenarios as given in $[8,11]$.

\section{SIMULATION AND IMPLEMENTATION}

In this work, simulation has been performed in Qualnet 6.1 using IEEE 802.15.4 framework. This framework was applied on WBAN. The IEEE 802.15.4 standard is adopted as a communication protocol for LR-WPAN which supports low data rate, less power consumption and short transmission distance. IEEE 802.15.4 is the basis for the Zigbee enabled WSNs. QualNet version 6.1 facilitates scalable simulations of WBAN. QualNet simulates the 802.15.4 protocol in PHY and MAC layers. The simulation determines the number of packets generated at source and those received at sink node, and also whether how many packets were dropped while accessing for the channel. The other important QoS parameters determined by simulation include network lifetime, delay, throughput, and number of alive nodes in the network. Figure 4 shows basic interface model for QualNet. It consists a number of components and processes. A three-dimensional body structure is assumed having dimensions $0.8 \mathrm{~m} * 1.8 \mathrm{~m} * 0.25 \mathrm{~m}$ corresponding $\mathrm{x}, \mathrm{y}, \mathrm{z}$ values. 12 nodes (11 nodes +1 sink) are placed on the front side of body and 4 nodes are deployed on back side. Deployments of various nodes on body have shown in Table 1. Figure 5 and figure 6 depicts $2-\mathrm{D}$ and 3-D view of node communication. All nodes will communicate to sink through shortest available route. 
TABLE 1.

NODE DEPLOYMENT

\begin{tabular}{cc} 
& NODE DEPLOYMENT \\
\hline Node & $\begin{array}{c}\text { Position }(\mathrm{X}, \mathrm{Y}, \mathrm{Z}) \\
(0.45,0.95,0.00)\end{array}$ \\
Node 1 (Sink) & Front Side Node \\
Node 2 & $(0.45,1.68,0.00)$ \\
Node 3 & $(0.35,0.95,0.00)$ \\
Node 4 & $(0.35,0.60,0.00)$ \\
Node 5 & $(0.57,0.48,0.00)$ \\
Node 6 & $(0.56,0.75,0.00)$ \\
Node 7 & $(0.75,0.63,0.00)$ \\
Node 8 & $(0.64,1.05,0.00)$ \\
Node 9 & $(0.55,0.16,0.00)$ \\
Node 10 & $(0.35,1.60,0.00)$ \\
Node 11 & $(0.43,1.25,-0.25)$ \\
& $(0.65,1.25,-0.25)$ \\
Node 12 & $(0.55,0.90,-0.25)$ \\
Node 13 & $(0.61,1.11,-0.25)$ \\
Node 14 & $(0.59,1.17,-0.25)$ \\
Node 15 & \\
Node 16 &
\end{tabular}

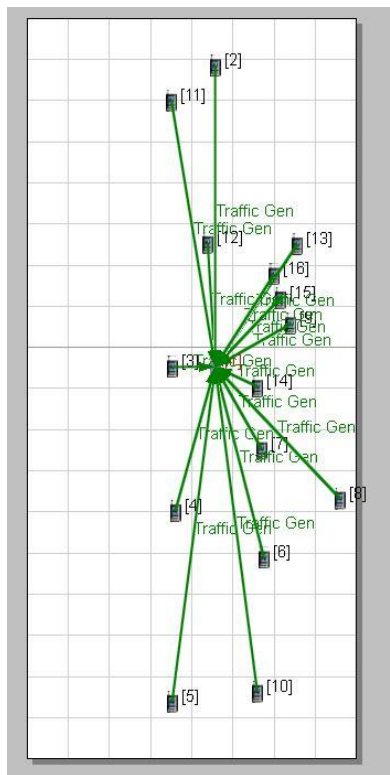

Figure. 5. 2D View of Node Communication

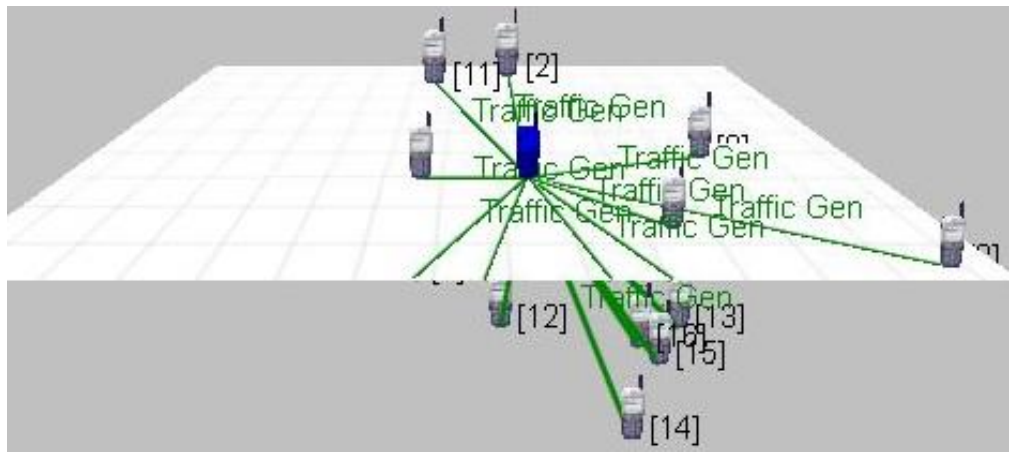

Figure. 6. 3D View of Node Communication

TABLE 2.

SIMULATION INPUTS

\begin{tabular}{cc}
\hline Parameters & Inputs \\
\hline Channel Frequency & $2.4 \mathrm{GHz}$ \\
Time taken for Simulation & $1 \mathrm{hr}$ \\
MAC protocol & IEEE 802.15.4 \\
Antenna type & Omni directional \\
Radio Type & IEEE 802.15.4 \\
Packet reception model & PHY 802.15.4 \\
Routing Protocol & LAR1, ZRP ,DYMO,DSR \\
Network Protocol & IPv4 \\
Beacon order & 5 \\
Super frame order & 3 (fixed) \\
Application & Traffic generator \\
CCA mode & Carrier-sense \\
Energy Model & MICAZ \\
\hline
\end{tabular}

Table 2 showed thirteen input parameters used in this simulation and their inputs. They are channel frequency, simulation time, protocol used, packet reception model, routing protocol, network protocol, beacon protocol, super frame order, application, CCA mode, and Energy model. The output parameters are packet delivery ratio, throughput, average end to end delay and jitter. A bodyarea-network link should support bit rates between $10 \mathrm{~kb} / \mathrm{s}$ and $10 \mathrm{Mb} / \mathrm{s}$, the maximum radiated transmitter power should be $0 \mathrm{dBm}$ (or $1 \mathrm{mw}$ ). These parameter were set for carrying out the simulation. 


\section{RESULTS}

Figure 7 depicts total number of messages received by the sink in the simulated time which is taken as 60 minutes. DSR outperforms other routing techniques such as DYMO, LAR1 and ZRP. DYMO performed better as compared to LAR1 and ZRP but lesser than DSR.

Lower the value of end to end delay, higher the performance. Figure 8 illustrated that ZRP had lowest average unicast end to end delay and DYMO had highest average unicast end to end delay. Throughput is defined as total number of packet received divided by total number of packets sent. It is measured in bits per second (b/s) [8]. The throughput of various protocols has been compared. Simulation results showed that DSR have better throughput as compared to other protocols with in simulated time as shown in figure 9. Jitter defines time difference between successive packet arrival which is caused due to network congestion, timing drift or route changes. It should be low. DYMO has had highest jitter value as compared to other routing protocols, while DSR, ZRP and LAR1 have very less jitter below 0.5 as shown in figure 10. Table 3 showed comparative analysis of DYMO, ZRP, DSR and LAR1 with respect to parameters such as total unicast message received, throughput, jitter, end to end delay.

口DYMO $\square$ ZRP $\square D S R \quad \square L A R 1$

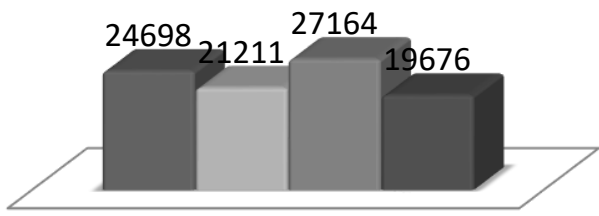

Total Unicast messages received (messages)

Figure. 7. Comparison of various protocols w.r.t. total unicast message received

$$
\square \text { DYMO } \square \text { ZRP } \quad \text { DSR } \quad \text { LAR1 }
$$

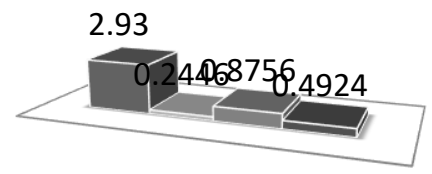

Average Unicast End to End

Delay (seconds)

Figure. 8. Comparison of various protocols w.r.t. average unicast end to end delay (s)

$\square$ DYMO $\square$ ZRP $\square$ DSR $\square$ LAR1

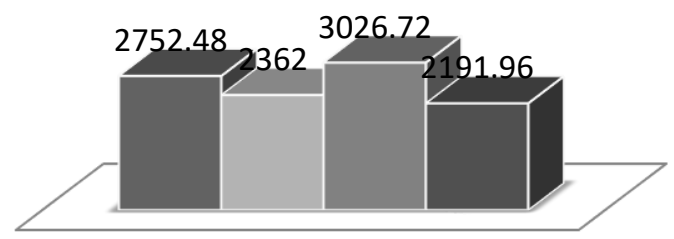

Throughput (bits/sec)

Figure. 9. Comparison of various protocols w.r.t. throughput(b/s) 
- DYMO $\square$ ZRP $\square$ DSR $\square$ LAR1

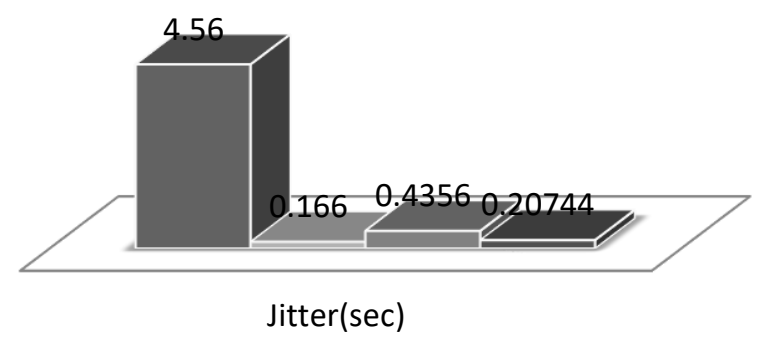

Figure. 10. Comparison of various protocols w.r.t. jitter (s)

TABLE 3 .

COMPARISON OF VARIOUS PROTOCOLS BASED ON VARIOUS PARAMETERS

\begin{tabular}{lllll}
\hline Protocols & $\begin{array}{l}\text { Total Unicast messages received } \\
\text { (messages) }\end{array}$ & $\begin{array}{l}\text { Average Unicast End to End Delay } \\
(\mathrm{s})\end{array}$ & Throughput (b/s) & Jitter(s) \\
\hline DYMO & 24698 & 2.93 & 2752.48 & 4.56 \\
ZRP & 21211 & 0.2446 & 2362 & 0.166 \\
DSR & 27164 & 0.8756 & 3026.72 & 0.4356 \\
LAR1 & 19676 & 0.4924 & 2191.96 & 0.20744 \\
\hline
\end{tabular}

\section{CONCLUSION}

In this work, various MANET routing protocols have been compared with respect to WBSN. The comparisons have been shown in terms of total unicast message received, throughput, jitter, end to end delay. Results showed that ZRP, which works like Intrazone and Interzone routing performed better as compared to other protocols (DSR, DYMO and LAR1). ZRP have least end

\section{REFERENCES}

[1] Laurie Hughes, Xinheng Wang and Tao Chen, "A review of protocol implementations and energy efficient cross-layer design for wireless body area networks", Sensors (Basel, Switzerland), pp.14730-14773, 2012.

[2] Waluyo, A.B., Yeoh, W.-S., Pek, I.; Yong, Y., Chen, X.," MobiSense: Mobile body sensor network for ambulatory monitoring," ACM Trans. Embedded Computer System, Volume 10 No 1, pp. 1-30, August 2010.

[3] B. Latre et al., "A survey on wireless body area networks", Wireless Network, vol. 17 no. 1, pp. 1-18, Jan.2011.

[4] D. Cypher, N. Chevrollier, N. Montavont, and N. Golmie,"Prevailing over wires in healthcare environments: benefits and challenges", IEEE Communications Magazine, vol. 44, no. 4, pp.56-63.

[5] Tsouri, Gill R., Alvaro Prieto, Nikhil Argade, "On increasing network lifetime in body area networks using global routing with energy consumption balancing", Sensors (Basel, Switzerland), Volume 12 no 10, 2012, pp. 13088-13108.

[6] Y. Zhou, Z. Sheng, V. C. M. Leung and P. Servati, "Beacon-based opportunistic scheduling in wireless body area network," 2016 38th Annual International Conference of the IEEE Engineering in Medicine and Biology Society (EMBC), Orlando, FL, 2016, pp. 4995-4998.

[7] David Oliver Jorg, "Performance comparison of MANET routing protocols in different network sizes," in Institute of Computer to end delay (0.2) and jitter (0.1), but have low throughput i.e. $2362 \mathrm{~b} / \mathrm{s}$ as compared to DYMO and DSR i.e. $2752 \mathrm{~b} / \mathrm{s}$ and $3026 \mathrm{~b} / \mathrm{s}$. DSR have highest number of packets received (27164) as well as throughput (3026.72 b/s). LAR1 have less jitter (0.2) and end to end delay (0.4) as compared to DSR and DYMO. The throughput and packet delivery ratio of DYMO is least as compared to other routing techniques.

Science and Applied Mathematics Computer Networks and Distributed Systems (RVS) Switzerland: University of Berne, 2003.

[8] Zayene M.A., Tabbane N. , "Performance evaluation of location aided routing protocols in ad hoc networks," Proceedings of the Second international conference on Global Information Infrastructure Symposium, Tunisia, June 22 - 26, 2009, pp. 22-27.

[9] I. Chakeres and C. Perkins, "Dynamic MANET On-demand (DYMO) routing draft-ietf-manetdymo-17" Internet Engineering Task Force, Mar. 2009. [Online]. Available:http://tools. ietf.org/html /draft-ietf-manet-dymo-17.

[10]P. Samundiswary and R. Surender, "Performance comparison of GTS mechanism enabled IEEE 802.15.4 based wireless sensor networks using LAR and DYMO protocol," 2014 International Conference on Electronics, Communication and Computational Engineering (ICECCE), Hosur, 2014, pp. 254-258.

[11] A. Awad, R. German and F. Dressler, "Exploiting virtual coordinates for improved routing performance in sensor networks," in IEEE Transactions on Mobile Computing, vol. 10, no. 9, pp. 1214-1226, Sept. 2011.

[12]T. E. Ali, L. A. Khalil al Dulaimi and Y. E. Majeed, "Review and performance comparison of VANET protocols: AODV, DSR, OLSR, DYMO, DSDV \& ZRP," 2016 Al-Sadeq International Conference on Multidisciplinary in IT and Communication Science and Applications (AIC-MITCSA), Baghdad, 2016, pp. 1-6.

[13] J. J. Ferronato and M. A. S. Trentin, "Analysis of routing protocols OLSR, AODV and ZRP in real urban vehicular scenario with density 
variation," in IEEE Latin America Transactions, vol. 15, no. 9, pp. 1727-1734, 2017.

[14] Samaneh Movassaghi, Mahyar, Mehran Abolhasan, "An Energy Efficient Network Coding Approach for Wireless Body Area Networks", 38th Annual IEEE Conference on Local Computer Networks, 2013, pp. 468-475.

[15] S. Ahmed, N. Javaid, S. Yousaf, A. Ahmad, M. M. Sandhu, Z. A. Khan, N. Alrajeh, M. Imran, "Co-LAEEBA: Cooperative Link Aware and Energy Efficient Protocol for Wireless Body Area Networks", Computers in Human Behaviour, vol. 51, 2015, pp. 12051215.

[16] Samaneh Movassaghi, Mehran Abolhasan, "Smart Spectrum Allocation for Interference Mitigation in Wireless Body Area
Networks", International Conference on Communication, IEEE, 2014, pp. 5688-5693.

[17] Sadaf Talha, Rizwan Ahmad and Adnan Khalid Kiani, "Priority Based Energy Aware (PEA) Routing Protocol for WBANs", 82nd Vehicular Technology Conference (VTC Fall), IEEE, 2015, pp. 1-5.

[18] Raju Sharma, Hardeep Singh Ryait, Anuj Kumar Gupta, "Clustering Based Routing Protocol to increase the stability in WBAN", International Journal of Innovations in Engineering and Technology, October 2015, pp. 119-125.

[19]Ilkyu Ha, "EECBSR (Even Energy Consumption and Back Side Routing): An Improved Routing Protocol for Effective Data Transmission in Wireless Body Area Networks", International Journal of Distributed Sensor Networks, vol. 12 no. 7, 2016,pp. 1-11. 